\title{
Anastomosis and Intraspecific Groups of Rhizoctonia solani
}

\author{
Riya Rachel Joji* and Meenakshi Rana \\ Department of Plant Pathology, School of Agriculture, Lovely Professional University, \\ Phagwara-144001, India \\ *Corresponding author
}

\section{A B S T R A C T}

Keywords

Rhizoctonia solani, cultivable and noncultivable soils, structural and chemical properties

Article Info

Accepted:

12 April 2021

Available Online: 10 May 2021
A soil pathogen which causes damping off and rotting in the seedlings in the nursery is caused by Rhizoctonia solani where its sexual stage is recognized as Thanatephorus cucumeris (Frank). It is a soil borne pathogen which leads to a huge loss in the field. the pathogen produces no such spores like conidia or conidiophores. It infects a wide range of hosts from vegetables to cereals in the field. appearance of the symptoms in the form of lesions on the infected parts of the plant were observed. Presence of mycelium was detected with septations and the branching were at $90^{\circ}$ that is., at right angles branching were observed. Till date, there are thirteen AGs recognized from the Rhizoctonia solani. The groups were designed based on the hyphal interactions among the pathogen.

\section{Introduction}

Among the cultivable and non-cultivable soils, Rhizoctonia solani and other Rhizoctonia species which is a soil-borne pathogen having a wide host range around the globe. When this pathogen is isolated from an infected plant part or from soil through serial dilution and when they are observed under the microscope there is slight variations in their physical characteristics, an ability or the capacity to cause disease, structural and chemical properties differ in the isolates of Rhizoctonia solani. On the basis of the differences obtained from the physical and biochemical variations among the isolates collected from Rhizoctonia solani there are ISGs known as the intraspecific groups of Rhizoctonia species.

But sometimes, it turns out to be a difficult task to differentiate the isolates obtained as there is a lack of original cultures which leads to a hinderance in the study of the mycology and the pathogenicity of the pathogen.

With the efforts of the researchers and the scholars this task has been resolved by characterizing Rhizoctonia and also its other species. In this article, we will learn about the 
anastomosis and the intraspecific groups of Rhizoctonia solani.

About the Pathogen Rhizoctonia and Rhizoctonia solani

The genus Rhizoctonia having about 100 or more was first described by De Candolle in 1815. On recognizing the pathogen Rhizoctonia, variation have been recorded and observed for recognizing and distinguishing the genus of the pathogen.

The ability to cause an infection, type of sclerotial formed and its structural and physical appearance helps in the differentiation of the pathogen Rhizoctonia. On the basis of the recorded observations, the genus Rhizoctonia belongs to the Basidiomycota fungal group which is an imperfect fungi having a mycelial appearance with septations, production of the sclerotia and the arrangement of the mycelia or the hypha is at right angles $\left(90^{\circ}\right)$, branching of the mycelium, with no clamp connections and absence of rhizomorph.

From the above descriptions, there are only 49 species of the Rhizoctonia considered as true species and others as duplicates or the copies of the pathogen.

From the above characterization, Rhizoctonia is been distinguished into three main groups under which they have been placed. Multinucleate Rhizoctonia: 3 or more nuclei with bigger hyphae or mycelia with its sexual stage as Thanatephorus.

Binucleate Rhizoctonia: only 2 nuclei having a small hyphae with its sexual stage as Ceratobasidium.

Multinucleate and the sexual stage is Waitea: examples are as follows - Rhizoctonia oryzae and Rhizoctonia zeae.

\section{Rhizoctonia solani}

Anamorph is Rhizoctonia solani where its telomorph or the sexual or the perfect fungi is Thanatephorus cucumeris which have a wide host range and distributed to vast areas where the soil is having higher moisture and temperature. In the past there were few crucial findings and were added in the studies of the pathogen Rhizoctonia solani where its clearance of the pathogen as a species, the findings of the intraspecific groups (ISGs) and also the findings of the telomorph of Rhizoctonia solani were discovered for the proper classification and also in the study of the pathology. There were many findings by different scientists related to the pathogen but in the later years Parameter and Whitney described about the characteristic features of Rhizoctonia solani where they said that the telomorphic stage is Thanatephorus cucumeris where the hyphal arrangement having 2 or more than 2 nuclei per cell and also the formation of the sclerotial stage and thus according to Parameter et al., Rhizoctonia is also to be categorized under Rhizoctonia solani.

\section{Intraspecific Groups of Rhizoctonia Solani}

As the pathogen Rhizoctonia solani, it has a wide range of hosts around the globe. Based on its physical properties, its appearance on the culture medium, ability to cause infections in the host, formation of the sclerotia and its structures, Rhizoctonia solani have an $\mathrm{N}$ number of intraspecific groups and on these groups the pathogen Rhizoctonia solani are categorized.

This categorization is also based on the anastomosis of the hyphae of Rhizoctonia solani that is the hyphal association of the pathogen isolates obtained from the different hosts or from the same host. 
Categorization on the Basis of the Morphology

Categorizing of Rhizoctonia solani were being conducted by Exner, who experimented and divided the pathogen into following f.sp's (forma specialis) as solani, microsclerotia, sasakii and timsii which were identified in the pathogen Thanatephorus cucumeris.

These were an addition to the forma specialis mainly named as compacta and betae as recorded by Takahashi and Matsuura were the scientists who added the other two and thus there are six divisions of forma specialis of Rhizoctonia solani. Earlier the pathogen that caused sheath blight of rice was Hypochnus sasakii which was included as form a specialis sasakii which was recorded by Watanabe and Matsuda and this was studied in the location from Japan. The above named scientists collected about 220 isolates of Rhizoctonia solani from Japan which had been grouped into 7:

Sasakii which is a typq IA

Web blight IB

Winter crops (II)

Praticola (III-A)

Potato (IV)

Root rot (IV)

Compacta

Betae

Above mentioned compacta and betae were categorized by Takahashi and Matsuura which had a contradiction with the four forma specialis.

\section{Anastomosis Hyphal Association}

At a lower resolution power, if growth and overlapping of mycelium occurs when two isolates of Rhizoctonia solani are placed on the same culture media in the petri plate with content of $2 \% \mathrm{H}_{2} \mathrm{O}$ agar in a light microscope. Hyphal attraction and the lysis of the cells that being fused are recorded in an association of the two hyphae then the isolates obtained comes under the same anastomosis group. If there is no association between the hyphae and if there is no lysis then the Rhizoctonia solani isolates are grouped under varied anastomosis groups. To detect an associated hyphae, fusion and lysis are the recorded methods to identify. There were 5 anastomosis groups identified by Schultz and are as follows which are the Rhizoctonia solani varieties;

hortensis

brassicae

Typica

Cichorii endiviae

juchsiae

From the above, group $\mathrm{V}$ is not considered as Rhizoctonia solani as it is having two nuclei per cell. There were 6 anastomosis groups as reported by Schneider and Richter and are as follows- A, B, C, D (Brassicae), E and F (Potato) where ' $\mathrm{E}$ ' is having two nuclei per cell and is categorized as bi-nucleate. On the basis of the fusion, Rhizoctonia solani was reported to grouped into 4 AGs as follows, AG I, AGII, AG III and AG IV by Parmeter $e t$ al., There was a study in which there is crossing of the isolates of Rhizoctonia solani having the capability to cross with the members of more than two AGs. Similarly, on the basis of fusion of hyphae, Ogoshi divided Rhizoctonia solani from Japan into different categories. 


\section{Hyphal Fusion and its Mechanism}

Following is the procedure of a hyphal fusion of the pathogen Rhizoctonia solani is when there is association of the protoplasm, cell wall termination, construction of the shoot like protruding structures, growth of the hyphae, secretion of few attractant chemicals, hyphal contact, growth of the hyphae gets ceased is known to be a perfect hyphal association. The imperfection is then occurred when there is a differentiation in the termination of the cell walls and then followed up by the lysis of the cells. Fusion of the hyphae is possible when the isolate identifies of its same category or the isolate belonging to the same anastomosis group. There will be a curiosity of how an isolate identifies and fuses with the other hypha. The answer was been discussed in the morphology of the AG that is, the attractant chemicals and the connection because the bonding is due to the attractant substances released. At a distance of $100 \mu \mathrm{m}$, the hyphae of an isolate identify the another with the change of direction in the growth of the tip of the hypha to another tip of the hypha till there is a proximity. This type of association is made once the hypha releases the attractant chemical belonging to the family of the anastomosis group. From the study of the attractant chemicals it was recorded that these chemical substances released differ among the members of the different or the varied anastomosis groups. Thus, its relevant that the release of the attractant is the initial step and then occurs the fusion of the hyphae. As mentioned in the morphology it is evident that all the process starts with the recognizing followed by the growth of the hyphal tip, cell wall of both the isolates being dissolved.

\section{Anastomosis Groups and its Interrelations}

As per the records, Parmeter et al., the fusion of the hyphae occurs in the cross of the isolates obtained in Japan with the 4 AGs having about 12 isolates. From the above resulted that the anastomosis groups considered by Parmeter et al., were similar to the Japanese anastomosis groups. Also there is a similarity between the anastomosis groups considered by Schultz with that of the anastomosis groups of Richter and Schneider. The similarity also occurred in the anastomosis groups obtained from the countries as follows Europe, North America and Japan with that of the anastomosis groups reported by Watanabe and Matsuda.

According to Ogoshi, anastomosis group numbered $\mathrm{V}$ had a similarity with that of anastomosis group B recorded by Richter and Schneider. The confirmation was reported by B. Nirenburg with the fusion of group B6 with the anastomosis group numbered $\mathrm{V}$ Rhizoctonia solani isolates. The multinucleated Rhizoctonia solani having 3 or more nuclei per cell which belongs to the anastomosis group numbered $\mathrm{V}$, with a property similar to Thanatephorus cucumeris. In other aspects, anastomosis groups numbered BI, VI and VII had a similar property with that of the telemorphic stage of Thanatephorus cucumeris.

\section{AGs and ISGs of Rhizoctonia solani}

\section{Reported AGs}

From the earlier reports, it was observed that Schultz discovered 4 anastomosis groups followed by Richter and Schneider gave 5 and Parmeter et al., gave 4 groups. Later, in Australia anastomosis group numbered VIII was reported and 8 anastomosis groups in which there were sub-anastomosis groups were also reported in Japan. However, with the current observations and relevant evidences Rhizoctonia solani have about 9 AGs around the globe. But according to Parmeter et al., there could more AGs as estimated earlier. Also, at the earliest Carling 
et al., have reported the findings of a new AG numbered IX from Alaska.

\section{Telomorphic Stages with AGs and ISGs}

B. Frank in 1863 was the first one to report the telomorphic stage of Rhizoctonia solani as Thanatephorus cucumeris earlier which was known as Hypochnus cucumeris. There are documents where there is publishing of the telomorphic stages of Rhizoctonia solani.

Observation of the sexual stages and the categorization of Rhizoctonia solani into 4 f.sp groups were formulated by Exner where she stated by saying that basidium are not the basis of differentiation. Some of the isolates obtained from Rhizoctonia solani from the soil on which there is formation of the hymenium. Through this technique he collected the telomorphic stages of varied Rhizoctonia solani isolates given by Flentje and this technique had a vital role in helping other researchers in the further discoveries. Using this soil clump method, the sexual stages and the anastomosis groups numbered I, II (1 and 2), III, $1 \mathrm{~V}$ and V of Rhizoctonia solani which were concluded by Ogoshi. In the later papers, it was concluded that the telomorphic stage Thanatephorus cucumeris had 13 intraspecific groups. After reviewing all the papers related to the ISGs it was concluded that the categorization of the AGs would be a difficult task on the basis of the physical characters like as mentioned about the hymenium, basidium, etc. Here taking an example anastomosis group numbered IV, are differentiated among the other 4 anastomosis groups is that the former has the presence of sterigmata. On the other hand, the intra-specific groups have also some deformities is that not all the groups are formed on the basis of the telomorphic stages and here the pathogen Rhizoctonia solani is categorized not based on the other species but solani remains the main focus due to its wide distribution in most of the places, the colonization, the physical characteristics and the sequenced DNA content.

Thus, after all the contradicting debate, they came to a conclusion that the pathogen Rhizoctonia solani has the telomorphic stage as Thanatephorus cucumeris and the scientist who gave the taxonomic classification of Rhizoctonia solani by Talbot.

Below is the classification:

\section{Kingdom}

Fungi Phylum: Basidiomycota

Class: Agaricomycetes

Order: Ceratobasidiales

Family: Ceratobasidiaceae

Genus: Rhizoctonia

Species: solani

\section{ISGs and its Importance}

On the basis of anastomosis groups, Rhizoctonia solani the researches have not gained the complete knowledge but this anastomosis grouping is also essential. It is not necessary that the particular anastomosis group will cause the infection in a host peculiarly and confined to a host specifically. For more better understanding we can an example, anastomosis group numbered I will cause rise sheath blight as well as other diseases caused in pulses by Rhizoctonia solani (web-blight). The degree of pathogenicity or the virulence factor is the basis on which anastomosis group I is again grouped into sub-groups namely AG IA and AG IB and were concluded by the Japanese scientists that these two belongs to the Rhizoctonia solani. The symptoms caused by 
the two sub-groups have a slight variation thus they are placed in different categories.

Thus, its evident that IA can cause disease on the host of IB but the variation comes in the virulence and severity of the infection caused by either of the one in another hosts. Soon after there was a comparative study between $H$. sasakii and $H$. cucumeris which caused diseases on the different hosts on the basis of formation of the sclerotia and then later on they were distinguished. And, another scientist Matsumoto with his scholars also tried to compare H. sasakii and Corticiumvagum with its telomorphic stage as Thanatephorus cucumeris, there was no fusion of the hyphae thus there was no such comparison obtained. Thus, they stated that these two belong to different species. There was also a study in which, Nakata and Kawamura concluded that there is no comparison on the sexual stage of these two but they found a variation in the structure of the sclerotia, their distribution, anastomosis groups and thus on the mentioned basis they have varied species. In Japan, the pathogen Rhizoctonia solani caused infection on plants like sugarbeet and buckwheat, and the anastomosis group numbered as I-IC which had an overlapping with IA followed by IB and IC. The fusion depends upon the compatibility between the members belonging to the same Anastomosis Group itself. If there is a variation in the fusion there will be a noncompatible fusion.

On the basis of the physical appearances on the culture medium, chemical and biochemical properties the isolates are distinguished with an accuracy in the case of anastomosis group numbered II- (III-B) and IV.

There is a difficulty in production of the protoplasts from the fusion of III-B with I-A or I-B as this fusion will result in the death of the cells. In this article we will get to see different anastomosis groups of Rhizoctonia solani with its varied genetics and biomolecular structures. Here, Rhizoctonia solani have 13 intra-specific groupings that have a variation and distinguishable characteristics such as its morphology, its capacity to cause an infection. Following are the 13 AGs:

AGI (IA), AGI (IB), AGII (I), AGII-2 (IIIB), AGII-2 (IV), AGIII, AGIV, AGV, AGVI, AGVII, AGVIII and AG-BI.

\section{AGs and ISGs on the Basis of Biology}

Following are the basis by which we can distinguish between the anastomosis groups and intra-specific groups of Rhizoctonia solani using the biological characteristics:

\section{Required Amount of Vitamins}

All the 13 intra-specific groups have different requirement of the nutrients on which they grow and colonize better. Some feed on the thiamine medium and thus called as auxotrophics which includes the following groups:

AG II-2-(IIIB)

AG II-2-(IV)

$\mathrm{AG}(\mathrm{V})$

AG-IB

Within the same AG, there is sub groups in which they also differ in the usage of the medium where the AG II-I which is an autotroph grows on thiamine, while the other AG-II-II, is an auxotroph.

In fact, AG-BI is known as the ancient member of Rhizoctonia solani. From the sources it was found that requirement of thiamine was not considered for a crucial role. Another autotroph that feeds on the thiamine 
is the AG-VIII which is considered as crossover isolate. Thus, on the basis of the requirement of the thiamine, it is easy to distinguish between the groups VIII and AGB-I. A study on auxotrophic C. sclerotia was done by Sadasivan and Subramanian, whereas there was a contradiction in which Sherwood said that the pathogen comes under the anastomosis group numbered I where the members of anastomosis group number I belongs to the autotrophs feeding on the thiamine.

In some of the papers it was evident to conclude that $C$. microsclerotia have many groups and not considered as one single pathogen. To increase the weight of the mycelia from $5 \%$ to $40 \%$, use of Calcium panthothenate is recommended basically in the mycelium production of the anastomosis groups numbered II-1, II-2-IIIB, II-2-IV, and V. Some other compounds are also responsible for their growth and multiplication which are initiated by the chemicals like folic acid, inositol, nicotinic acid, pyridoxine hydrochloride and riboflavin.

\section{Differentiation by Serological Techniques}

In one of the researches conducted by Abe et $a l$., where he said that an antiserum produced to reduce the rate of infection by Rhizoctonia solani by the anastomosis group II-II 4 which also quickly counteracted among the other isolates where they resulted in the formation of precipitin bands. The characteristics of the isolates causing a specific disease or an infection on a crop have similar serology streams. There are experiments where there was formation of just two precipitin bands in the case of the reaction between the antisera and the anastomosis groups numbered II-I, IIII-IIIB, IV and I-IA. In another case it was observed that there was no reaction between the anastomosis groups I-IB and E with antiserum. Here the anastomosis groups are collected from the bi-nucleate Rhizoctonia solani. The serology technical experiments were performed on the 6 different anastomosis groups of Rhizoctonia solani where Anastomosis Groups II-I and II-II were differentiated on the basis of serology as stated by Adams and Butler.

\section{Separation of Proteins and Isoenzymes}

The proteins of the intra-specific groups patterned in the PAGE gels has a distinguishable pattern apart from other proteins separated from DNA or any other organisms. Through the separation of these proteins have made a clear pathway to group the similar isolates within the same isolate anastomosis groups on the basis of the similar bands used in the identification of the Rhizoctonia solani. The recognition of the dissimilar patters through electrophoresis is done in the similarly occurring categories which was said by Kuninagain the same anastomosis groups. There has been a report on the comparison on the patterns of the proteins were concluded by the relation between the genetic and the anastomosis groups.

In this way, we can also detect specific enzymes with the help of the electrophoresis gel technique. In of the experiment it was observed that iso-enzyme esterase is a nonspecific which on comparison was done through electrophoresis and the result was varied amongst the intra-specific groups.

This proved to be an efficient method in distinguishing the various relations between the groups by conducting an electrophoresis test.

\section{Composition of DNA}

Basically, this DNA based determination is used in the identification, classification and taxonomy of bacteria genera. It is generally measured in the terms of GC content where 
the guanine in addition with the cytosine contents is measured in mole \%. Though used in the taxonomy of the bacteria it is also widely used in the fungi with filaments. Comparisons of the DNA constituents examined from the isolates will give rise to the relations of genetic and evolution amongst the anastomosis groups and the intra-specific groups.

Though there was a similarity in the GC content of the anastomosis groups of Rhizoctonia solani, but in meanwhile, there was a variation reported in the intra-specific groups mainly of the anastomosis group numbered I and II.

Similarities can be there but there should be no clone of one another. Thus, they should be considered as single individual on the basis of the genetics.

On the basis of the evolution of these fungal based on their GC contents then the ultimately advanced is the Anastomosis Group I-IA with $49 \%$ and the primordial is the Anastomosis Group is BI.

Isolates of the anastomosis group I-IA have a distinct physiology and ecology characters with specific causal organisms where it has become easier to the evolution of the anastomosis group. While the anastomosis group B-I has a characteristic that it can combine with the remaining anastomosis groups.

The fungal pathogens have a variation in their Guanine and Cytosine mole percent species to species which is less than or equal to $10 \%$.

Thus, we can come to a conclusion that the Intra-specific groups isolated from Rhizoctonia solani comes under the same species.

\section{Sequencing based on DNA}

Assessing genetic relations within the microbes use of hybridization of DNA technique has been widely used that can summarize the minute variations and other characteristics in the DNA of the fungal pathogens. Study of DNA structure is necessary for the breeder to make it an easy task in order to make the resistant varieties against the pathogen or the isolate of the AGs which is responsible in causing the infection. The isolates belonging to the same intraspecific groups had a higher number of the DNA sequence homology of about $90 \%$ or more than $90 \%$ while there was a lower number of the DNA homology which had range in between $30-90 \%$ in those isolates which does not belong to the same intra specific groups but of same Anastomosis Groups.

There was a study in which a specific anastomosis group had the capability of fusing with the other AGs which had the range of DNA sequence homology from $15-60 \%$ in the following groups: anastomosis groups BI, II-I, II-II, III and VI. Among the above group only Anastomosis Group B-I could do the fusion with the other groups.

In the rest of the groups, there is the least number of DNA sequence homology found about equal to or lesser that $14 \%$.There was discovery of a new groups named as Homogenous Group only in the anastomosis group numbered IV which was given by Kuninaga and Yokosawa. This groups were again sub-grouped into I and II in which the GROUP I had the DNA sequence homology in the range of $88.5 \%-92.6 \%$ in the 6 isolates collected. GROUP II in which there were 8 isolates containing the DNA homology in the range of $88.7 \%-103 \%$. When both of the GROUPS are distinguished then we get a lower number of the DNA homology ranging 
from $30.9 \%$ - 48\%. These groups are distinguished and grouped in two groups on the basis of their electrophorated proteins and the culture media observations.

Also, there was an observation in which there was the presence of the GROUP I in the anastomosis group numbered VI with a varied genotypic appearance. In this DNA sequence homology, we have 15 different ISGs isolated from Rhizoctonia solani which becomes a base in the differentiation between the anastomosis groups and the intra-specific groups. This basis of differentiation is possible in the fungi having filament like appearance.

\section{Groups on the Basis of Ecology and Pathogenicity}

In this section we will discuss about the different anastomosis groups and the intraspecific groups not taking just the topic of Rhizoctonia solani.

\section{Distribution around the Globe}

The origin of the Rhizoctonia solani and its isolates and different groups were first observed and recorded in Japan by Watanabe, Matsuda and Ogoshi.

The collected anastomosis groups, ISGs and the groups I and II were isolated and studied closely to understand their origin and distribution and also their host range. These were observed to be present in the ranges from temperate to sub-arctic in Japan.

The anastomosis groups kike BI, VI and VII are yet to be under close investigation. Maximum number of these groups are distributed in Japan. From previous reports the further studies are made out or modified to give these groups a better frame-work. Around the globe, it has been recorded that Anastomosis groups I, II, III and IV were isolated around the globe but in places like Canada, Germany and Israel anastomosis group V was reported. Also, the anastomosis group V was reported in Taiwan and USA. There was presence of the anastomosis group VI and VII in the following countries, Japan and Israel and the later were found in Japan. In Australia the presence of AG was VIII. Most of the Japanese cultivated soils consisted of the anastomosis group named B-I. VII anastomosis group was recorded in Scotland followed by the VI, VII, VIII and B-I reported to be properly observed in recent times. Thus, it can also be possibly found in other regions too but they were not recorded in a constant manner. There has also been an observation that there were two anastomosis groups VI and B-I were collected from the barren lands also.

In contrast with the above sentence, Kuninaga had an observation where he clarified that Anastomosis groups VI and BI were collected from the cultivable fields and these two isolates were collected from the species of the forest trees and not the crops. Now in later days it was also observed about the nonavailability of these two AGs were still a mystery topic.

In later times there was a source evident in revealing about the AGs being found only in the cultivable fields and they were as follows, anastomosis groups V, VIII and VIII. Till date the complete information and data is still under process to get the whole knowledge regarding the disbursement of the pathogen Rhizoctonia solani and its anastomosis groups.

\section{Host Range and its Disbursement}

Though the range of the pathogen is widely present around the globe but the anastomosis groups are limited and the spread of these anastomosis groups is also in limit in the fields of agriculture. This is because the exertion of the prevailing anastomosis group and its 
presence and its influencing capacity on the crops cultivated in a particular field.

Here, if legumes or rice, wheat is sown in a field then the chances of infection by the anastomosis group is AG-I. This group is mainly considered as the reason behind the increased rate of infection from the attack of Rhizoctonia solani, followed by the anastomosis groups like, I-IB and I-IA. The crucifers or the Brassicaceae family is infected by the anastomosis group II-I and the members of the amaranthaceae are mostly infected by anastomosis group II-II 4. The potato, brinjal crops are infected by the anastomosis group III and also IV group. From the soils of the field in which the legumes are grown had the traces and evidence of anastomosis group V. Even there was naming of the anastomosis groups like the groups infecting the crucifers was given the name as AG-II var. brassicae by Schultz and later it was again renamed by Richter and Schneider to AG-II var. cruciferin. Thus, each anastomosis groups have specific host range and they have different level of rate of infection on the host. Thus, from the above studies it is well known that anastomosis groups I, II, III, IV and V have different host range, varied characteristics, ecology and different level of infection on the host. Also, there are discovery of few other anastomosis groups like VI, VII, VIII and B-I but their ecology, the rate of infection, the virulence factor and its hosts are not specifically known.

\section{Fluctuating Populations in the Field}

When the environmental conditions are favourable for the infestations and increased virulence is possible only in the presence of the suitable host and the virulent pathogen to have a possible interaction. These are the basic requirements in the development of any disease or infection. There was increasing rate of Rhizoctonia solani in the fields during the months of July and then in the month of September. And in the alternate months there is decrease in the rate of infection which was reported by Vi et al., in 1983. As mentioned above about which anastomosis group is responsible in the pathogenicity of disease in which crop. The root rot of sugar-beet is caused by the anastomosis group numbered IIII stated by Inoue and Ui. Followed by the other group $\mathrm{V}$ that usually infected the bean crops. The increase in the infection by Rhizoctonia solani increases in the case of mono-cropping practiced in the crops like sugar-beet, bean crops, etc which came into limelight by the investigation done by Komoto et al., in 1932. In the same way few other anastomosis groups were collected from the sugar-beet fields consisting of the I, II-II and $\mathrm{V}$. With the increasing rate of the sugar beet root rot in the fields there is increased rate of collection of the II-II anastomosis group due to continuity of the mono-cropping but the incidence of other groups got declined. According to the crops associated with the specific anastomosis groups had an increase in their isolation from that particular respective fields. When the field infested with the Rhizoctonia solani causing infection in the beet crops also induced the infection in severe form on the radish crops sown in the same field which was observed by Yoshida and Kobayashi. Thus, the dependence of the anastomosis groups and the intra-specific groups on the hosts were playing a vital role in increasing rates of infection where the need of the rotation of the crop became needful.

\section{Resistance against Rhizoctonia solani}

As Rhizoctonia solani have a wide host range and also different isolates of anastomosis groups attack on the crops, it is difficult to maintain a specific resistant variety for each anastomosis groups or the intra-specific group of Rhizoctonia solani. 
But as mentioned above about the specificity of some anastomosis groups infecting a particular crop can help the breeder to develop a new variety that can resist the attack of Rhizoctonia solani and its isolates. This would be a tough job because a lot of genetic study is required to understand the core of each isolates associated with the infection. This was stated by Leach and Garber. As some groups are responsible for causing a virulent infection thus, the breeders have got the potentiality to raise resistant varieties against the particular anastomosis groups or the intra-specific groups of Rhizoctonia solani.

While isolating the pathogen it is not necessary to get the correct pathogen along with the appropriate anastomosis or the intraspecific groups but after getting the appropriate isolates can help the breeders to create the new resistant varieties against that particular anastomosis or the ISGs.

Thus, breeders need to know the specific group associated with the infection in the specific host so that the resistant variety can withstand the pathogen and reduce the yield loss in future.

\section{Epizootiological Functioning of Spore Borne on a Basidium}

Earlier Rhizoctonia solani was categorized under Deuteromycota group as it does not produce any spores but they only produce mycelia at right angles $\left(90^{\circ}\right)$ but now the sexual or the telomorphic stage have been identified thus placed under the Basidiomycota group as they produce the sexual spores known as basidiospores. But due to lesser known facts about the mechanisms of infection by these basidiospores and are yet to be known completely. The sexual or the telomorphic stage of Rhizoctonia solani is the Thanatephorus cucumeris usually infecting the roots of the plants and produces sclerotia in the soil or near the root areas. Production of the basidiospores were commonly observed on the foliar parts of the sugar-beet crops and the development of these basidiospores are still unknown or in the process of research as mentioned by Yamaguchi and Fuji.

There was a detailed study of the process how the spores infect the plant by the scientists Naito and Sugimoto where the infection was caused by the anastomosis group numbered IIII-IV. The basidiospores are formed either in the soil, root surfaces and sometimes on the foliar regions where they get transferred or blown away and gets attached to the plant parts and where there is formation of appressoria to penetrate into the epidermal cells and take the nutrition. The penetrated hypha later produces mycelium and then later forms rotund shaped sores known as lesions in the form of radial shaped. These sores are primary structures and these are the first symptoms to be observed. Later on, the lesions caused by the hypha enters into the foliar parts by the stomatal pores and the lesions produced by these hyphae is quite bigger and the symptoms give rise to blighted appearance.

The cycle is repeated in a uniform pattern from the dissemination of the spores, penetration, infection and formation and appearance of the symptoms like the primary and secondary lesions on the foliar parts. As there is spore formation, thus it is recommended to use the chemical fungicides that help in controlling the airborne diseases. Though the pathogen Rhizoctonia solani causes the major damage but it is deteriorated by the telomorphic stage that is, Thanatephorus cucumeris. For the better knowledge, study on the taxonomy and epidemiology of Rhizoctonia solani, has given a smooth pathway to learn about its ISGs in the similar way of the classification of Fusarium. There evolves a variation and 
similarities on the basis of ecology and epidemiology of Rhizoctonia solani. In a contrasting case, the sugar beet leaf blight whose pathogen is Rhizoctonia solani considered that the two highly varied distant fungi cause the blight by the anastomosis groups I IB and anastomosis group II-II IV. The first anastomosis group is responsible for the mycelium spread and the second mentioned anastomosis group is related to the dissemination of the mycelium and the spores produced in the basidium. Thus, while doing the management and control the knowledge is important in the fields of the anastomosis and the ISGs. In these studies, there is no complete knowledge of the ontogeny and the biorhythm of the intraspecific groups of Rhizoctonia solani.

There are more researches and investigations on the anastomosis groups going on the causal organism Rhizoctonia solani and yet to be in the lime light. The surviving structure of Rhizoctonia solani is the rounded uniform and non-uniform called the sclerotia which are formed by the Rhizotonia solani and also the ontogeny of the spores and its vital role in the fields were also yet to be understood more clearly. The observation of the spores on the stem were fine but the study on these spores and their functioning of these spores were yet to be studied closer and this was observed on the stems of the potato crop, which was infected by the anastomosis group III. Also, the same anastomosis group III that caused an infection on the potato also caused infections on the crops like brinjal and the tomato causing leaf spots. The investigation of the intraspecific groups based on its ecology and its aetiology of the Rhizoctonia solani for having a complete knowledge of each and every intra-specific groups.

Also, there is an incomplete information and also the knowledge of the multi-nucleic and bi-nucleic. As mentioned above of these Rhizoctonia, are usually isolated with the isolation of the Rhizoctonia solani. The binucleate and multi-nucleate is to be observed after proper identification using the biochemical properties. There are studies on the anastomosis and intraspecific groups of the other species other than Rhizoctonia solani but with lesser known facts and knowledge.

Thus, its necessary for the young researchers to have a closer look on the studies and experiments on the other species of Rhizoctonia solani.

\section{References}

Abdoulaye A H, Foda M F, Kotta-Loizou I. Viruses infecting the plant pathogenic fungus Rhizoctonia solani. Viruses. 2019 Dec;11(12):1113.

Adams G C. Thanatephoruscucumeris (Rhizoctonia solani), a species complex of wide host range. Advances in plant pathology. 1988 Jan 1;6:535-52.

Ajayi-Oyetunde O O, Bradley C A. Rhizoctonia solani: taxonomy, population biology and management of rhizoctonia seedling disease of soybean. Plant pathology. 2018 Jan;67(1):3-17.

Aliferis K A, Jabaji S. FT-ICR/MS and GC-EI/MS metabolomics networking unravels global potato sprout's responses to Rhizoctonia solani infection. PLoS One. 2012 Aug 3;7(8):e42576.

Alghuthaymi M A. Cultural, anastomosis, and universally primed PCR typing of Rhizoctonia solani from potato. Biosciences Biotechnology Research Asia. 2018 Mar 25;15(1):119-30.

Anderson N A. The genetics and pathology of Rhizoctonia solani. Annual review of phytopathology. 1982 Sep;20(1):329-47.

Anees M, Edel-Hermann V, Steinberg C. Build up of patches caused by Rhizoctonia solani. Soil Biology and Biochemistry. 2010 Oct 1;42(10):1661-72.

Arakawa M, Inagaki K. Molecular markers for genotyping anastomosis groups and understanding the population biology of Rhizoctonia species. Journal of general 
plant pathology. 2014 Sep 1;80(5):401-7.

Balali G R, Neate S M, Scott ES, Whisson D L, Wicks T J. Anastomosis group and pathogenicity of isolates of Rhizoctonia solani from potato crops in South Australia. Plant Pathology. 1995 Dec;44(6):1050-7.

Bandy B P, Zanzinger D H, Tavantzis S M. Isolation of anastomosis group 5 of Rhizoctonia solani from potato field soils in Maine. Phytopathology. 1984 Jan 1;74(10):1220-4.

Bharathan N, Saso H, Gudipati L, Bharathan S, Whited K, K. Anthony. Double- stranded RNA: distribution and analysis among isolates of Rhizoctonia solani AG- 2 to- 13. Plant Pathology. 2005 Apr;54(2):196-203.

Budge G E, Shaw M W, Colyer A, Pietravalle S, Boonham N. Molecular tools to investigate Rhizoctonia solani distribution in soil. Plant Pathology. 2009 Dec;58(6):1071-80.

Campion C, Chatot C, Perraton B, Andrivon D. Anastomosis groups, pathogenicity and sensitivity to fungicides of Rhizoctonia solani isolates collected on potato crops in France. European Journal of Plant Pathology. 2003 Nov 1;109(9):983-92.

Carling D E, Kuninaga S, Brainard K A. Hyphal anastomosis reactions, rDNA-internal transcribed spacer sequences, and virulence levels among subsets of Rhizoctonia solani anastomosis group-2 (AG-2) and AG-BI. Phytopathology. 2002 Jan;92(1):43-50.

Ceresini P C, Shew H D, James T Y, Vilgalys R J, Cubeta M A. Phylogeography of the Solanaceae-infecting Basidiomycota fungus Rhizoctonia solani AG-3 based on sequence analysis of two nuclear DNA loci. BMC Evolutionary Biology. 2007 Dec $1 ; 7(1): 163$.

Copley T R, Duggavathi R, Jabaji S. The transcriptional landscape of Rhizoctonia solani AG1-IA during infection of soybean as defined by RNA-seq. PloS one. 2017 Sep 6;12(9):e0184095.

Cubeta M A, Vilgalys R. Population biology of the Rhizoctonia solani complex. Phytopathology. 1997 Apr;87(4):480-4.

Cubeta M A, Echandi E, Abernethy T, Vilgalys R. Characterization of anastomosis groups of binucleate Rhizoctonia species using restriction analysis of an amplified ribosomal RNA gene. Phytopathology. 1991 Nov 1;81(11):1395-400.

Demirci E. Rhizoctonia species and anastomosis groups isolated from barley and wheat in Erzurum, Turkey. Plant Pathology. 1998 Feb;47(1):10-5.

Drizou F, Bruce T J, Ray R V, Graham N S. Infestation by Myzuspersicae Increases Susceptibility of Brassica napus cv. "Canard" to Rhizoctonia solani AG 2-1. Frontiers in plant science. 2018 Dec 21;9:1903.

El- Tarabily K A. Suppression of Rhizoctonia solani diseases of sugar beet by antagonistic and plant growth- promoting yeasts. Journal of Applied Microbiology. 2004 Jan;96(1):69-75.

El-Samawaty A M, Amal A, Asran M R, Omar Abd-Elsalam K A. Anastomosis groups, pathogenicity, and cellulase production of Rhizoctonia solani from cotton. Pest Technology. 2008;1(2):117-24.

Erlacher A, Cardinale M, Grosch R, Grube M, Berg G. The impact of the pathogen Rhizoctonia solani and its beneficial counterpart Bacillus amyloliquefaciens on the indigenous lettuce microbiome. Frontiers in Microbiology. 2014 Apr 21;5:175.

Fenille R C, Ciampi M B, Kuramae E E, Souza N L. Identification of Rhizoctonia solani associated with soybean in Brazil by rDNAITS sequences. Fitopatologia Brasileira. 2003 Aug;28(4):413-9.

Fiers M, Edel-Hermann V, Chatot C, Le Hingrat Y, Alabouvette C, Steinberg C. Potato soilborne diseases. A review. Agronomy for Sustainable Development. 2012 Jan 1;32(1):93-132.

Foley R C, Gleason C A, Anderson J P, Hamann T, Singh K B. Genetic and genomic analysis of Rhizoctonia solani interactions with Arabidopsis; evidence of resistance mediated through NADPH oxidases. PLoS One. 2013 Feb 25;8(2):e56814.

Foley R C, Kidd B N, Hane J K, Anderson J P, Singh K B. Reactive oxygen species play a role in the infection of the necrotrophic fungi, Rhizoctonia solani in wheat. PLoS One. 2016 Mar 31;11(3):e0152548. 
Gao L L, Smith F A, Smith S E. The rmc locus does not affect plant interactions or defence-related gene expression when tomato (Solanum lycopersicum) is infected with the root fungal parasite, Rhizoctonia. Functional Plant Biology. 2006 Mar 23;33(3):289-96.

Ghosh S, Gupta S K, Jha G. Identification and functional analysis of AG1-IA specific genes of Rhizoctonia solani. Current genetics. 2014 Nov 1;60(4):327-41.

Giovannetti M, Azzolini D, Citernesi A S. Anastomosis formation and nuclear and protoplasmic exchange in arbuscular mycorrhizal fungi. Applied and Environmental Microbiology. 1999 Dec 1;65(12):5571-5.

Gómez Expósito R, De Bruijn I, Postma J, Raaijmakers J M. Current insights into the role of rhizosphere bacteria in disease suppressive soils. Frontiers in Microbiology. 2017 Dec 18;8:2529.

Gondal A S, Rauf A, Naz F. Anastomosis Groups of Rhizoctonia solani associated with tomato foot rot in Pothohar Region of Pakistan. Scientific reports. 2019 Mar 7;9(1):1-2.

Grosch R, Scherwinski K, Lottmann J, Berg G. Fungal antagonists of the plant pathogen Rhizoctonia solani: selection, control efficacy and influence on the indigenous microbial community. Mycological Research. 2006 Dec 1;110(12):1464-74.

Gurkanli C T, Ozkoc I, Gunduz I. Molecular and conventional identification and pathogenicity of Rhizoctonia solani isolates from tobacco (Nicotiana tabacum L.) in Samsun, Turkey. Journal of phytopathology. 2009 Dec;157(11-12):68696.

Hane J K, Anderson J P, Williams A H, Sperschneider J, Singh K B. Genome sequencing and comparative genomics of the broad host-range pathogen Rhizoctonia solani AG8. PLoS Genet. 2014 May 8;10(5):e1004281.

Hayden H L, Savin K W, Wadeson J, Gupta V V, Mele $P$ M. Comparative metatranscriptomics of wheat rhizosphere microbiomes in disease suppressive and non-suppressive soils for Rhizoctonia solani
AG8. Frontiers in microbiology. 2018 May 4;9:859.

Helmy M M, Emad G, Samir E D, Mostafa MH. Phenotypic diversity and molecular identification of the most prevalent anastomosis group of Rhizoctonia solani isolated from diseased faba bean plants. American Journal of Life Sciences. 2015 Feb 13;3(1):47-55.

Hua G K, Bertier L, Soltaninejad S, Höfte M. Cropping systems and cultural practices determine the Rhizoctonia anastomosis groups associated with Brassica spp. in Vietnam. PloS one. 2014 Nov 5;9(11):e111750.

Hyakumachi M, Mushika T, Ogiso Y, Toda T, Kageyama K, Tsuge T. Characterization of a new cultural type (LP) of Rhizoctonia solani AG2- 2 isolated from warm- season turfgrasses, and its genetic differentiation from other cultural types. Plant Pathology. 1998 Feb;47(1):1-9.

Ji L, Liu C, Zhang L, Liu A, Yu J. Variation of rDNA internal transcribed spacer sequences in Rhizoctonia cerealis. Current microbiology. 2017 Jul 1;74(7):877-84.

Khodayari M, Safaie N, Shamsbakhsh M. Genetic Diversity of Iranian AG1- IA Isolates of Rhizoctonia solani, the Cause of Rice Sheath Blight, Using Morphological and Molecular Markers. Journal of Phytopathology. 2009 Dec;157(11- 12):708-14.

Kotba I, Achouri M, Benbouazza A, Touhami AO, Douira A. Morphological, pathogenic and molecular characterisation of Rhizoctonia solani strains isolated from potato. Annual Research \& Review in Biology. 2018 Nov 26:1-6.

Lahlali R, Hijri M. Screening, identification and evaluation of potential biocontrol fungal endophytes against Rhizoctonia solani AG3 on potato plants. FEMS microbiology letters. 2010 Oct 1;311(2):152-9.

Lakshman D K, Jian J, Tavantzis S M. A doublestranded RNA element from a hypovirulent strain of Rhizoctonia solani occurs in DNA form and is genetically related to the pentafunctional AROM protein of the shikimate pathway. Proceedings of the National Academy of Sciences. 1998 May 
26;95(11):6425-9.

Le Cointe R, Simon T E, Delarue P, Hervé M, Leclerc M, Poggi S. Reducing the use of pesticides with site-specific application: the chemical control of Rhizoctonia solani as a case of study for the management of soilborne diseases. PloS one. 2016 Sep 26;11(9):e0163221.

Lees A K, Cullen D W, Sullivan L, Nicolson M J. Development of conventional and quantitative real- time PCR assays for the detection and identification of Rhizoctonia solani AG-3 in potato and soil. Plant Pathology. 2002 Jun;51(3):293-302.

Lehtonen M. Rhizoctonia solani as a potato pathogen: Variation of isolates in Finland and host response.

Li S, Peng X, Wang Y, Hua K, Xing F, Zheng Y, Liu W, Sun W, Wei S. The effector AGLIP1 in Rhizoctonia solani AG1 IA triggers cell death in plants and promotes disease development through inhibiting PAMP-triggered immunity in Arabidopsis thaliana. Frontiers in microbiology. 2019 Sep 26;10:2228.

Li H R, Wu B C, Yan S Q. Aetiology of Rhizoctonia in sheath blight of maize in Sichuan. Plant Pathology. 1998 Feb;47(1):16-21.

Losada L, Pakala S B, Fedorova N D, Joardar V, Shabalina SA, Hostetler J, Pakala SM, Zafar N, Thomas E, Rodriguez-Carres M, Dean R. Mobile elements and mitochondrial genome expansion in the soil fungus and potato pathogen Rhizoctonia solani AG-3. FEMS microbiology letters. 2014 Mar 1;352(2):165-73.

MacNish G C, Carling D E, Sweetingham M W, Brainard K A. Anastomosis group (AG) affinity of pectic isozyme (zymogram) groups (ZG) of Rhizoctonia solani from the Western Australian cereal-belt. Mycological Research. 1994 Dec 1;98(12):1369-75.

MacNish G C, Carling D E, Brainard K A. Relationship of microscopic and macroscopic vegetative reactions in Rhizoctonia solani and the occurrence of vegetatively compatible populations (VCPs) in AG-8. Mycological Research. 1997 Jan 1;101(1):61-8.
Matthew J, Whisson D. DNA probe specific to Rhizoctonia solani anastomosis group 8 . Mycological Research. 1995 Jun 1;99 (6):745-50.

Mohammadi M, Banihashemi M, Hedjaroude G A, Rahimian $H$. Genetic diversity among Iranian isolates of Rhizoctonia solaniKühn anastomosis group1 subgroups based on isozyme analysis and total soluble protein pattern. Journal of Phytopathology. 2003 Mar;151(3):162-70.

Montealegre J R, Reyes R, Pérez L M, Herrera R, Silva $P$, Besoain $X$. Selection of bioantagonistic bacteria to be used in biological control of Rhizoctonia solani in tomato. Electronic Journal of Biotechnology. 2003 Aug;6(2):115-27.

Moni Z R, Ali M A, Alam M S, Rahman M A, Bhuiyan M R, Mian M S, Iftekharuddaula K M, Latif M A, Khan M A. Morphological and genetical variability among Rhizoctonia solani isolates causing sheath blight disease of rice. Rice Science. 2016 Jan 1;23(1):4250.

Mughal M N, Bashir S, Bhat N A, Bhat K A. Cultural and morphological variability and identification of anastomosis group of Rhizoctonia solani (Thanatephorus cucumeris) causing sheath blight of rice in Khasmir. Int J CurrMicrobiol App Sci. 2017;6:3787-94.

Muzhinji N, Truter M, Woodhall J W, Van der Waals J E. Anastomosis groups and pathogenicity of Rhizoctonia solani and binucleate Rhizoctonia from potato in South Africa. Plant Disease. 2015 Dec 14;99(12):1790-802.

Nadarajah K, Razali N M, Cheah B H, Sahruna N S, Ismail I, Tathode M, Bankar K. Draft genome sequence of Rhizoctonia solani anastomosis group 1 subgroup $1 \mathrm{~A}$ strain $1802 / \mathrm{KB}$ isolated from rice. Genome Announcements. 2017 Oct 26;5(43).

Neate S M, Warcup J H. Anastomosis grouping of some isolates of Thanatephorus cucumeris from agricultural soils in South Australia. Transactions of the British Mycological Society. 1985 Dec 1;85(4):615-20.

Ogoshi A. Ecology and pathogenicity of anastomosis and intraspecific groups of Rhizoctonia solani Kuhn. Annual review of 
phytopathology. 1987 Sep;25(1):125-43.

Oladzad A, Zitnick-Anderson K, Jain S, Simons $\mathrm{K}$, Osorno J M, McClean P E, Pasche J. Genotypes and genomic regions associated with Rhizoctonia solani resistance in common bean. Frontiers in Plant Science. 2019;10:956.

Pannecoucque J, Höfte M. Interactions between cauliflower and Rhizoctonia anastomosis groups with different levels of aggressiveness. BMC Plant Biology. 2009 Dec 1;9(1):95.

Parmeter J R, editor. Rhizoctonia solani, biology and pathology. Univ of California Press; 1970.

Peterson R L, Uetake Y, Zelmer C. Review article Fungal Symbioses with Orchid Protocorms. Symbiosis. 1998.

Picarelli M A, Forgia M, Rivas E B, Nerva L, Chiapello M, Turina M, Colariccio A. Extreme diversity of mycoviruses present in isolates of Rhizoctonia solani AG2-2 LP from Zoysia japonica from Brazil. Frontiers in cellular and infection microbiology. 2019;9:244.

Qu P, Yamashita K, Toda T, Priyatmojo A, Kubota M, Hyakumachi M. Heterokaryon formation in Thanatephorus cucumeris (Rhizoctonia solani) AG-1 IC. Mycological research. 2008 Sep 1;112(9):1088-100.

Salamone A L, Okubara P A. Real-time PCR quantification of Rhizoctonia solani AG-3 from soil samples. Journal of Microbiological Methods. 2020 Apr 6:105914.

Samsatly J, Copley T R, Jabaji S H. Antioxidant genes of plants and fungal pathogens are distinctly regulated during disease development in different Rhizoctonia solani pathosystems. PLoS One. 2018 Feb 21;13(2):e0192682.

Scherwinski K, Grosch R, Berg G. Effect of bacterial antagonists on lettuce: active biocontrol of Rhizoctonia solani and negligible, short-term effects on nontarget microorganisms. FEMS microbiology ecology. 2008 Apr 1;64(1):106-16.

Schneebeli K, Mathesius U, Zwart A B, Bragg J N, Vogel J P, Watt M. Brachypodiumdistachyon genotypes vary in resistance to Rhizoctonia solani AG8.
Functional plant biology. 2016 Feb 1;43(2):189-98.

Sharon M, Kuninaga S, Hyakumachi M, Sneh B. The advancing identification and classification of Rhizoctonia spp. using molecular and biotechnological methods compared with the classical anastomosis grouping. Mycoscience. 2006 Dec 1;47(6):299-316.

Sharon M, Sneh B, Kuninaga S, Hyakumachi M, Naito S. Classification of Rhizoctonia spp. using rDNA-ITS sequence analysis supports the genetic basis of the classical anastomosis grouping. Mycoscience. 2008 Apr 1;49(2):93-114.

Shih H D, Liu Y C, Hsu F L, Mulabagal V, Dodda R, Huang J W. Fungichromin: a substance from Streptomyces padanus with inhibitory effects on Rhizoctonia solani. Journal of agricultural and food chemistry. 2003 Jan 1;51(1):95-9.

Singh A, Shahi JP. Banded leaf and sheath blight: an emerging disease of maize (Zea mays L). Maydica. 2012 Dec 7;57(3):215-9.

Stodart B J, Harvey P R, Neate S M, Melanson D L, Scott E S. Genetic variation and pathogenicity of anastomosis group 2 isolates of Rhizoctonia solani in Australia. Mycological research. 2007 Aug 1;111(8):891-900.

Strausbaugh C A, Eujayl I A, Panella LW, Hanson L E. Virulence, distribution and diversity of Rhizoctonia solani from sugar beet in Idaho and Oregon. Canadian journal of plant pathology. 2011 Apr 11;33(2):210-26.

Sturrock C J, Woodhall J, Brown M, Walker C, Mooney SJ, Ray RV. Effects of dampingoff caused by Rhizoctonia solani anastomosis group 2-1 on roots of wheat and oil seed rape quantified using X-ray Computed Tomography and real-time PCR. Frontiers in plant science. 2015 Jun $24 ; 6: 461$.

St. Ępniewska- Jarosz S, Mańka M, Asiegbu FO. Studies on anastomosis groups of Rhizoctonia solani isolates causing disease in two forest nurseries in Poland. Forest Pathology. 2006 Apr;36(2):97-109.

Toda T, Hyakumachi M. Heterokaryon formation in Thanatephorus cucumeris anastomosis group 2-2 IV. Mycologia. 2006 Sep 
1;98(5):726-36.

Tsror L. Biology, epidemiology and management of Rhizoctonia solani on potato. Journal of Phytopathology. 2010 Oct;158(10):649-58.

Ünal F, Sara Dolar F. First report of Rhizoctonia solani AG 8 on wheat in Turkey. Journal of Phytopathology. 2012 Jan;160(1):52-4.

Verwaaijen B, Wibberg D, Kröber M, Winkler A, Zrenner R, Bednarz H, Niehaus K, Grosch R, Pühler A, Schlüter A. The Rhizoctonia solani AG1-IB (isolate 7/3/14) transcriptome during interaction with the host plant lettuce (Lactuca sativa L.). PloS one. 2017 May 9;12(5):e0177278.

Vilgalys R, Cubeta M A. Molecular systematics and population biology of Rhizoctonia. Annual Review of Phytopathology. 1994 Sep;32(1):135-55.

Wibberg D, Rupp O, Blom J, Jelonek L, Kröber M, Verwaaijen B, Goesmann A, Albaum S, Grosch R, Pühler A, Schlüter A. Development of a Rhizoctonia solani AG1IB specific gene model enables comparative genome analyses between phytopathogenic R. solani AG1-IA, AG1-IB, AG3 and AG8 isolates. PloS one. 2015 Dec 21;10(12):e0144769.

Wibberg D, Jelonek L, Rupp O, Hennig M, Eikmeyer F, Goesmann A, Hartmann A, Borriss R, Grosch R, Pühler A, Schlüter A. Establishment and interpretation of the genome sequence of the phytopathogenic fungus Rhizoctonia solani AG1-IB isolate 7/3/14. Journal of biotechnology. 2013 Aug 20;167(2):142-55.

Woodhall J W, Lees A K, Edwards S G, Jenkinson P. Infection of potato by Rhizoctonia solani: effect of anastomosis group. Plant Pathology. 2008 Oct;57(5):897-905.

Woodhall J W, Lees A K, Edwards S G, Jenkinson P. Characterization of Rhizoctonia solani from potato in Great Britain. Plant Pathology. 2007 Apr;56(2):286-95.

Xia Y, Fei B, He J, Zhou M, Zhang D, Pan L, Li S, Liang $\mathrm{Y}$, Wang L, Zhu J, Li P. Transcriptome analysis reveals the host selection fitness mechanisms of the Rhizoctonia solani AG1IA pathogen. Scientific reports. 2017 Aug 31;7(1):1-6.

Yang G, Li C. General description of Rhizoctonia species complex. INTECH Open Access Publisher; 2012 Apr 4.

Yildiz A, Döken M T. Anastomosis group determination of Rhizoctonia solani Kühn (telemorph: Thanatephorus cucumeris) isolates from tomatoes grown in Aydin, Turkey and their disease reaction on various tomato cultivars. Journal of Phytopathology. 2002 Oct;150(10):526-8.

Yu G Y, Sinclair J B, Hartman G L, Bertagnolli B L. Production of iturin A by Bacillus amyloliquefaciens suppressing Rhizoctonia solani. Soil Biology and Biochemistry. 2002 Jul 1;34(7):955-63.

Zachow C, Grosch R, Berg G. Impact of biotic and a-biotic parameters on structure and function of microbial communities living on sclerotia of the soil-borne pathogenic fungus Rhizoctonia solani. Applied soil ecology. 2011 Jun 1;48(2):193-200.

Zala M, McDonald B A, De Assis J B, Ciampi M B, Storari M, Peyer P, Ceresini P C. Highly polymorphic microsatellite loci in the rice- and maize- infecting fungal pathogen Rhizoctonia solani anastomosis group 1 IA. Molecular Ecology Resources. 2008 May;8(3):686-9.

ZENG Y X, JI Z J, LI X M, YANG C D. Advances in mapping loci conferring resistance to rice sheath blight and mining Rhizoctonia solani resistant resources. Rice Science. 2011 Mar 1;18(1):56-66.

\section{How to cite this article:}

Riya Rachel Joji and Meenakshi Rana. 2021. Anastomosis and Intraspecific Groups of Rhizoctonia solani. Int.J.Curr.Microbiol.App.Sci. 10(05): 324-340.

doi: https://doi.org/10.20546/ijcmas.2021.1005.040 